\title{
EVOLUTION FROM OPERATIONS PROJECT MANAGEMENT TO STRATEGIC PROJECT MANAGEMENT: A SYSTEMATIC REVIEW
}

\author{
R. Vivek \\ Sri Lanka Technological Campus, Sri Lanka \\ arvivek46@gmail.com \\ Y. Nanthagopan \\ Faculty of Business Studies, \\ Vavuniya Campus of the University of Jaffna \\ ynanthagopan@yahoo.com
}

\begin{abstract}
This article aims to review the evolution of Strategic Project Management (SPM) from Operations Project Management (OPM) in today's dynamic organizations. SPM identifies and implements the organization's long-term goals and objectives on the project while OPM takes care of completing projects within scope, time, budget, and quality parameters. Organizations are now encouraged to establish SPM practices for the success of organizations. This study was conducted by reviewing 16 published journal articles. The researchers identified how project management (PM) has advanced from operation to strategic perspectives and how it helps modern organizations achieve competitive advantage. Additionally, the researchers emphasized the challenges of SPM implementations in organizations. The study contributed theoretically to exploring the evolution of SPM concepts as a lack of SPM paucity in the literature and contributed in a practical way to organizations to understand the importance of SPM for their organizational success.
\end{abstract}

Keywords: Operational Project Management; Strategic Project Management; Competitive Advantage and Systematic Review

Journal of Business Studies, 7(2)

$-96-$

2020 


\section{Introduction}

The concept of strategy in society is not new; its origin had its roots in the youth of writing about war, published in famous works such as The Art of War by Sun Tzu (1994), first written around $400 \mathrm{BC}$. The first philosophers of war had no difficulty in defining strategy. They saw it as a quest to locate the simplest way to ensure the war or battle was won. Usually, they outlined different strategies and adapted them to the conditions that seemed most suitable. Therefore, within the military, strategy was a transparent concept, and it had focused on only one thing: how to win the war. Within the era, the concept of strategy has expanded to additional aspects of life. The term strategy is now used in different settings and much broader contexts, including the organizational settings, commonly see strategy as a direction, a plan, a guide, a longterm course of action, or a path to go from the present to the future.

PM is often differentiated by two main approaches: strategic project management and operations project management. SPM differs from strategic organizational management in that it involves determining the fit of specific projects to achieve the overall strategy of a corporation (Papke-Shields, 2017). SPM is narrowed down and takes into consideration the strategy of a private project, which can focus on systems design and provides a basis for determining the main objectives. Therefore, SPM is often defined as the management actions that are incorporated into a project to satisfy a strategic objective of a project by adjusting not only time, cost and resources, but also support to achieve the overall objectives and competitive advantage of an organization.

On the other hand, OPM is often defined as the management actions that are incorporated to meet the goal of a project by adjusting time, cost, and resources. In other words, they are often represented due to the steps taken to realize a described project strategy (Munro, 2018). Therefore, one of the main differences between strategic and operational PM is that OPM does not include changing the objective. Therefore, to form an operational decision, a group of activities is extracted from a project, with the idea that they will be discrete and that there will be well-defined information on time, cost and resources. Then, a discrete analysis is performed to detect the consequences of varying time, cost and resources to achieve the defined objectives. This is often the domain that usual PM tools focus on. However, for a successful implementation of SPM, a group of activities and parties involved in a project cannot be treated separately. Rather, they should be identified as ongoing 
elements of a project. In this way, a strategic decision is often made considering the impact of the choice on a project as a whole, not even as the sum of the impact on individual parts of the project (Lee et al., 2006).

SPM and OPM have their advantages and disadvantages. For example, implementing SPM helps a project manager look at decisions within the overall performance pattern and behaviour of a project. But SPM lacks the potential to quantify detailed impacts. On the other hand, the OPM projects is in a position to quantify the detailed impacts of a project, but the given objectives, as well as information on time, cost and resources, can be easily changed, for example, by the request to change an owner. Therefore, making good assumptions for OPM is unpredictable and, in particular, tied to SPM. However, to effectively manage a project, both strategic and operational approaches are required simultaneously (Kopmann et al., 2017).

Especially in project portfolios, which is a set of programs and projects that organizations often adopt strategy. This influences the culture, the values, the direct impact on the financial values and the effective use of the organisation's resources (Janka \& Kosieradzka, 2019). Grundy (1998) highlights that the profile of project management has become high profile in the application of strategies in project management. Many jobs are entering a remarkable transition in the way they are incorporated for social purposes and integration with the environment. A study on "The Paradoxical Profession: Project Management and the Contradictory Nature of Sustainable Project Goals" conducted by Sabini \& Alderman, (2021), investigated situations where PM as a profession is expected to work with limited sustainability. The study further stated that project managers are under pressure when talking about the sustainability of projects. Organizational barriers, temporal objectives and lack of control were found to be the aspects seen as limitations of the study objectives. Depending on the context of the project, the project managers seem to disappear, rejecting the organizations as their jobs are involved with the traditional objectives of the project. However, according to Grundy, (1998) PM is considered a Strategic Implementation agent. This interest in carrying out a strategic implementation increased the efficiency of their application, the concept of PM and what could be done through it. The objective of this systematic review is to review the evolution of SPM from OPM in the modern organisations and challenges faced by the organisations in implementing SPM. 


\section{Research Methodology}

The study adopted the systematic review that uses specific techniques to locate, select and critically appraise relevant primary research on a clearly established topic and then uses those findings to extract and analyze data from the past studies (Aromataris, 2014). The systematic review presents previous work that describes and evaluates the research examined, but does not provide a process for how the studies were discovered, chosen and evaluated. Instead, an overview, a discussion of previous studies, and a critique of the gaps in existing knowledge that researchers often use to explain the new findings to focus on interventions of various views (Denyer, 2009).

In the field of OPM and SPM it is an emerging field. However, to date, no framework or even a well-defined definition of SPM has evolved (Patanakul, 2012: Økland, 2015). The study identified the SPM gap as a knowledge gap, and an informative review is required in the context of SPM. The lack of maintenance of the system leads to a degradation of the validity, precision and usefulness of systematic reviews. Therefore, a unique technique will be used for updating the systematic review that we call a "live systematic review" (LSR). In this method, systematic reviews are updated, continually integrating new information. Many policies or practice choices are at risk from new evidence if research findings emerge quickly, existing results are disputed, and further research may alter the status quo. Therefore, this article adopted a systematic review to present articles from previous reviews in an informative way to fill the gap in SPM.

\subsection{Date Sources of the Study}

The study used 16 published journal articles. Table 1 provides the data sources that have been used for the systematic review process. The articles selected for this study are based on globally accepted high-ranking index data sources. Table 2 provides details of the data source and confirms the reliability and validity of the data source. All articles have been published in Scimago Ranking with Scopus Index. 


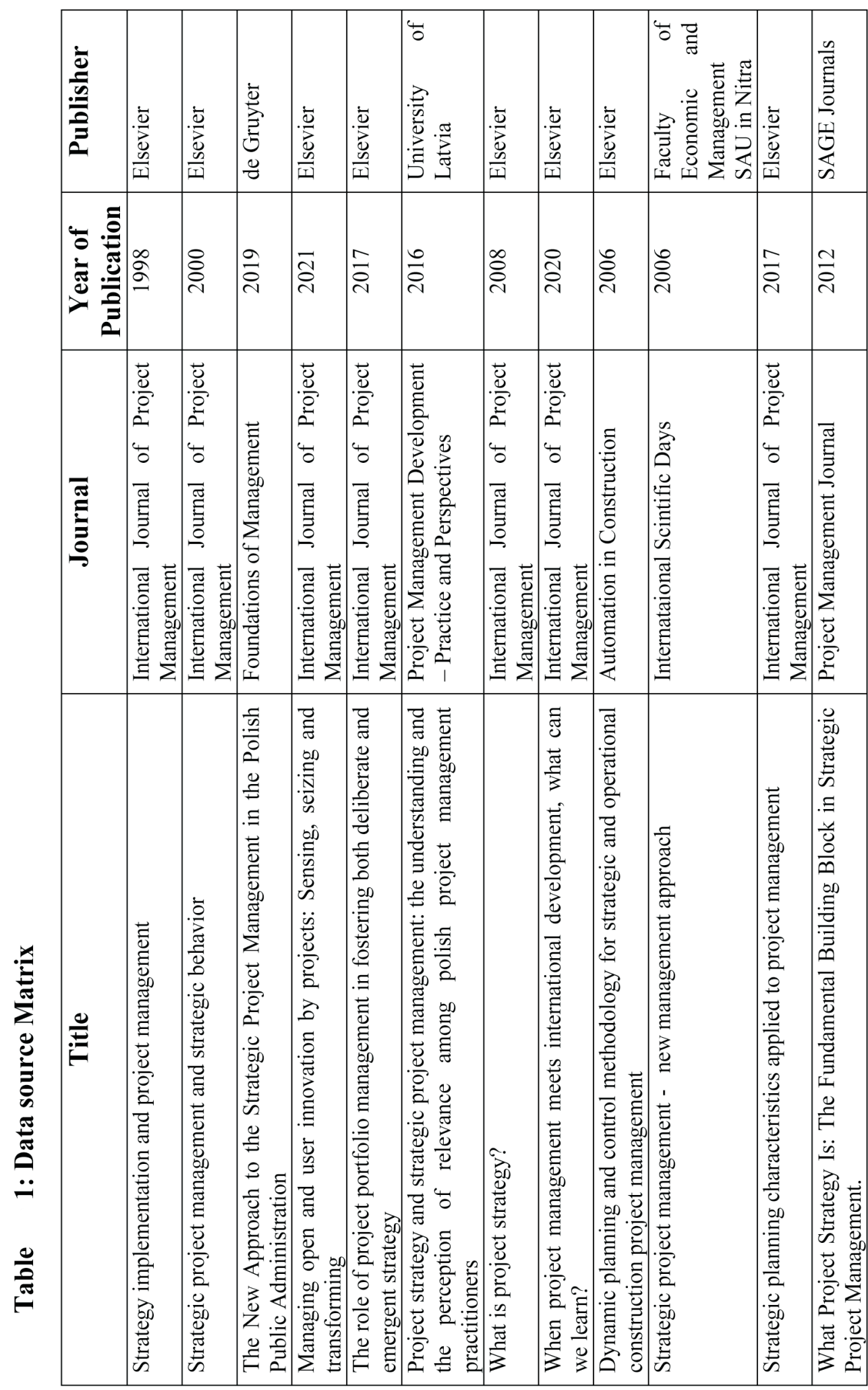

Journal of Business Studies, 7(2)

-100 - 

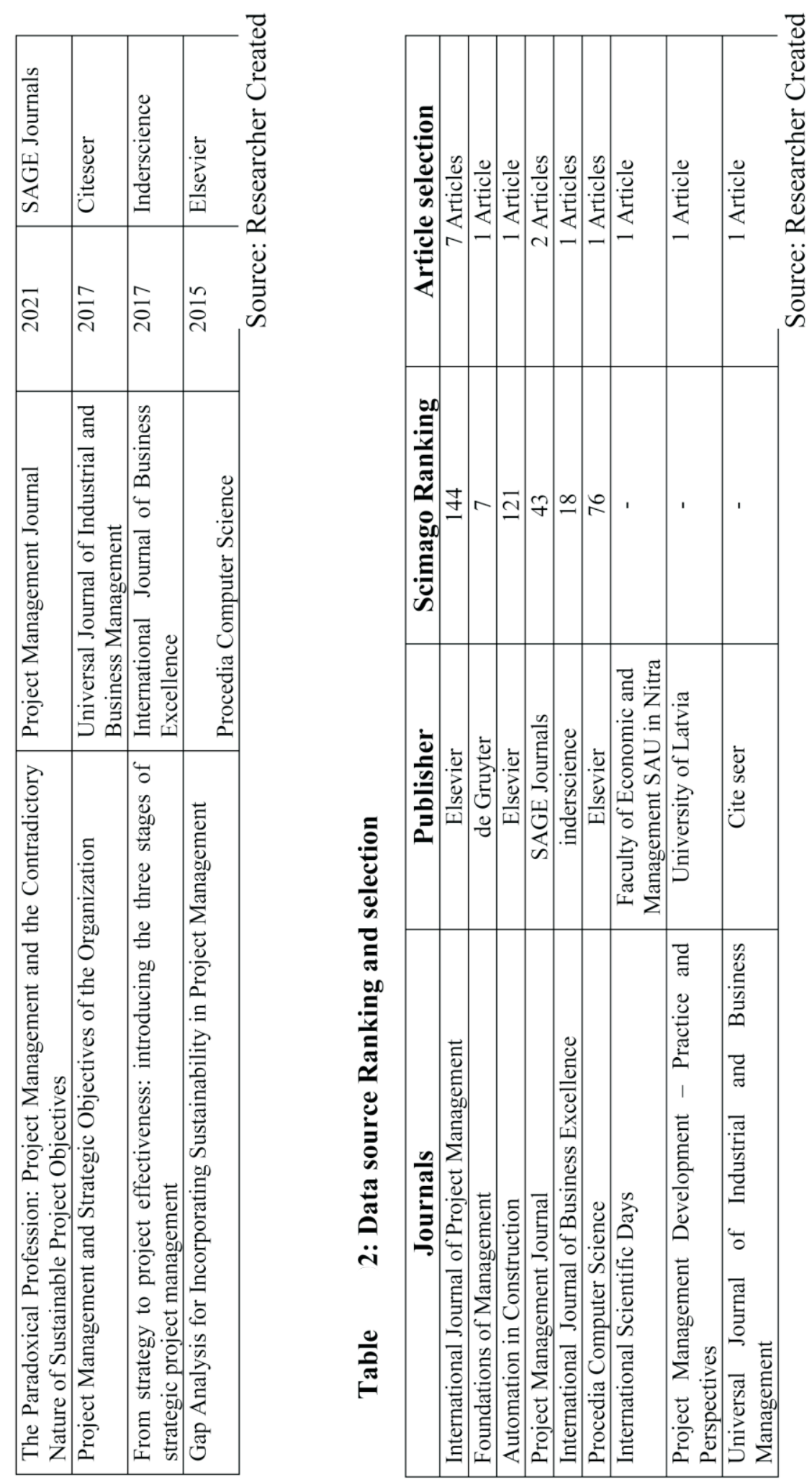


\section{Literature Review}

\subsection{Evolution of Strategic Project Management}

SPM is a popular and growing trend is slowly sweeping the business world. The main idea behind this concept is based on the PM team learning how to support the organisation's strategy and solve the business aspects of the project. Instead of just focusing on traditional OPM issues: budgets, goals, and deadlines. Aubry et al., (2007) proposed three complementary aspects : (1) translate the strategy into portfolios, programs, and projects; (2) generate synergy in the management of related initiatives; and (3) planning for the future of the organization.

The first point to mention is that PM at the strategic level (including programs and project portfolios) is seen as a method of putting the organisation's strategy into practice. Translating strategy into programs and projects is often considered a critical step in business (Jamieson \& Morris, 2004). Although these writers acknowledge that project strategy management has not been adequately studied in the business and project literature, they believe that this is an area that needs to be investigated. Another recent empirical study shows that not all organizations are successful in connecting projects and strategic objectives (Dietrich and Lehtonen, 2005).

A second aspect of strategic alignment is the synergy generated by the management of linked initiatives. In other words, the performance associated with the overall management exceeds the sum of the performance of the results of each project. For example, in the particular literature on platform approaches (Fernez-Walch and Garel, 2004) and programs and project portfolios (Fernez-Walch and Garel, 2004), one can discover the identification of advantages associated with the management of these links (Kendall and Rollins, 2003; Thiry and Matthey, 2005). From now on, these advantages can easily be the result of wishful thinking, as they have not been proven by rigorous empirical study. A third aspect of SPM has to do with planning for the future, and is rarely discussed in detail in the SPM literature. For example, in relation to the progression to PM maturity (Cooke-Davies, 2004) and the development of resource skills in PM (Cooke-Davies, 2004).

The functional approach within an organization requires an understanding of the various components of the organization. Mintzberg created a model of the components of an organization, each of which had a specific purpose (Mintzberg, 1979, 1983). He defined an organization as a collection of multi-level systems that 
interact with each other. The operating core, the middle line, the strategic vertex, the technostructure and the support staff were defined by him in his historical book (1979), which served as the basis for organizational theory and practice. PM is a component of the technostructure. Unlike the activities of the line of operation, which are carried out by employees who are responsible for the main activity of the organization, the technostructure is a function of the personnel. Technostructural workers are analysts who "perform administrative tasks: officially planning and supervising the work of others." Mintzberg (1979). Internal coalitions are made up of individuals who work within the organization on a global scale and exert a series of effects on the organization's power structure. At the time Mintzberg created this model, the science of PM was still in its infancy, with only a handful of practitioners (Kerzner, 2019). PM success is now directly related to global economic development (Bredillet et al., 2010). PM has spread beyond its traditional domains (military, defense, and engineering) and is now found in almost all industrial areas (Kerzner, 2019).

Keinz et al., (2021) conducted a study on "Special topic: Management of open and user innovation by projects: Sensing, seizing, and transforming ". This was done by reviewing existing PM-related articles to investigate certain factors in each article to identify open source issues, such as projects to sensing, seizing, and transforming various parts of communities. This study, derived from a study by Guertler and Sick (2021), investigated the effects of enabling project management in small and mediumsized enterprises (SMEs). This happened by analyzing the system problem, stakeholders, and partner collaboration in various case studies. This specific study found that PM can enhance its open and user-friendly approach to supporting projects into actionable form. In the same study, Keinz et al, (2021) investigated "What about people? Micro-foundations of open innovation in megaprojects". The findings in this paper discuss the effectiveness of open collaboration between industry and universities to manage megaprojects. The authors of this research found that the practical application of projects will improve when capable people are absorbed by the projects. This will be in addition to organizational capacity, including various innovation-related capabilities.

Kozarkiewicz \& Kabalska (2016) said that a frequent problem was reported during 2015 in the PM literature. The broader acceptance of PM is necessary to run a successful business. However, SPM is slowly emerging as a research topic. Although 
PM and SPM are evolving, there is no concrete strategic orientation or common definition for SPM. The terms Project Strategy and SPM have different formations. The results of the study show that although the project strategy is considered focused and important, it is not yet clear. Instead, knowledge and experience described the social impact across all different variations of understanding of PM and SPM.

Organizations are trying to achieve the desired level of competitiveness, success, and competitive advantage through the core competencies of strategic managementn (Vivek, 2020). These attempts are observed as failure due to the lack of effectiveness between the projects and the organizational objectives. In an organizational framework and due to competition in the market, project management has a higher priority than the efficiency and effectiveness of the project (Zolfaghari et al., 2017).

Project managers in PM play an important role and are noted as influential in decision making and stimulate projects to achieve many goals. Behaviors such as motivation and task orientation of the project manager will contribute to the success of the projects, since these behaviors will be an implication of their personal principles (Sabini \& Alderman, 2021). Traditional OPM focuses primarily on results, task coordination, and resource allocation. The traditional style of projects is mainly tangible concepts. But in the new form of SPM, it includes the strategic analysis in the implementation and includes the soft intangible components of the project and the project manager. In the new PM design, the design includes cycles that include instantaneous changes in the cycle. This influences the implementation process. This act breaks the linear action. When instantaneous changes are introduced in the cycle, strategic action and analysis remove the limit of strategic action. The blur phase eliminates a separate phase for strategic analysis and helps project management to implement it strategically. PM is an area that requires strategic implementation to create social problems in projects and operate them genuinely (Grundy, 1998).

\subsection{Strategic Project Management Views}

A review of the literature of different studies was carried out to identify the project strategies. The researchers found that an organization's project strategy allows an open interpretation of the content of project strategies that depend on the environment, as well as the strategy formulation and implementation processes. The Project strategy, also presented by the authors, recognizes that different positions in the same project can take place in the same environment. (Kujala et al., 2008). The project strategy is 
also defined as the project's perspective, position and guidelines on what to do and how to do it, to achieve the greatest competitive advantage and the best value of the project (Patanakul \& Shenhar, 2012).

The objectives and the environment of the project are not only to build products and services, but also to have a competitive advantage. Therefore, a suitable strategy for the project will lead to reaching that position. Therefore, the project strategy is the specific way in which the project will make this victory happen. In this way, the unique approach, direction and path of the project that are planned to win the commercial battle will be involved (Patanakul and Shenhar, 2012).

According to Patanakul \& Shenhar (2012), the distinction between the project strategy and the plan is that a plan is more about how to disseminate the project, but the strategies are not projected plans, they are the core of improvement of that plan. When strategies are identified, the plan helps decide tactics. This includes important ideas, including the success of the project. From regular planning, the strategy can be established as perspectives, guidelines, attitudes, direction and policies, the main factors of the current plan, the pattern of behaviour and the factors necessary to achieve success. A good strategy implies effectiveness and efficiency. Doing the projects correctly will be the proper SPM instead of doing the projects just to complete the project.

Project management should be organized with specific characteristics rather than factors such as planning, partner incorporation, monitoring and supervision, as well as organic communication, interaction effects and formal planning with low bureaucratic level would increase project performance (Keinz, et al., 2021). Now business sector research and development are ready to allow external actors to assist with innovative ideas. Because, the dynamic capacities to sustain projects are found when the floor is open to external people with different capacities to operate an organization (Keinz, et al 2021). In the PM stream, many studies are taken in conjunction with sustainability and PM. Due to this coupled concept, it is now being identified as a new school of thought within the mainstream and is now known as sustainable PM. Despite the current, the corporate and public spheres are also transforming from their traditional PM to add environmental and social aspects. When lower-level indicators are set to higher-level sustainability goals, conflict arises. Therefore, it is necessary to incorporate daily decisions to achieve sustainable development (Sabini \& Alderman, 2021). 
A study entitled "The New Approach to Strategic Project Management in Polish Public Administration" by Janka \& Kosieradzka (2019) discusses how to standardize project and program management methods in public administration. The intensity of political interference, organizational transactions between organizations and the environment, and bureaucratic structures define public and private organizations. According to research conducted by the Project Management Institute in 2013, worldwide there are 51 million people involved in project management. The research identified that the main driver of change in PM is stakeholder motivation. Public stakeholders often do not consider competition in the field. Therefore, when the private sector involves, depending on the long- and short-term goals, the motivation is necessarily considered in a high position in the private sector. So, the model in the public sector is probably a management-oriented man, while the private sector operates with an economy-oriented man. According to Patanakul \& Shenhar, (2012), stated that strategy is doing different things, or doing the same things differently, and emphasized that operational effectiveness and competitive advantage.

There is a relationship found in the establishment of the organizational strategy to increase the efficiency of the SPM. This is shown as a roadmap to achieve the vision and mission of the organization. Deriving the strategic objectives from the organization's mission and vision would increase the efficiency of being successful through SPM. The example that can be cited is that having feasible criteria does not only select projects (Singh, 2017). Almost two decades ago, PM techniques were rarely used in organizations, which were used mainly for being timely in the completion of projects, since project management rotates only in time, cost and scope. In this circle, the achievement of strategic objectives or goals is the achievement of the strategic objectives of the organization. The importance of the strategies is taken after the completion of the project, so the funding organization may express their disappointment, although the results are clear and delivered well, they may be ineffective as a complete project. Therefore, Singh, (2017) affirms that a broader vision of the development of organizational strategies would help the projects to have the SPM as an organization.

Strategic behavior is defined as "the cognitive, emotional and territorial interaction of managers within (or between) groups when the agenda is related to strategic issues". The emotional, cognitive, emotional and territorial support of the program managers is interconnected with the SPM. However, these factors are less discussed with 
managers, as they are endowed with power or emotional sensitivities. According to Marko et al., (2006) PM is primarily results-oriented, has a high demand for effective leadership, consistent meetings with stakeholders, and the expected ability to find synergies and merge toward the goal through multidisciplinary teams with those assigned mobilization and use of resources.

\subsection{Challenges of Implementing SPM}

Unless strategies are implemented, there will be no consequences for an organization. Many organizations face the challenge of implementing rather than planning. Because the implementation is quite difficult from the planning and formulation of the strategy. Many organizations have used the help of project management to implement their strategic management (Cullen et al, 2015). One of the most important events that an organization faces is achieving the objectives with the restricted resources offered. A number of resources are forever linked to operational problems and cannot be used to achieve the stated goals of the organization. If an organization turns these strategic objectives into action, then the action conceives to deliver the goods. These goals are achieved through project management.

Project management tools, such as the work breakdown structure (dividing work into small work items), responsibility matrix, and network analysis, can solve problems like who can do what and when can we achieve goals required. In addition, observation techniques will facilitate maintaining control over the specified objectives and what modifications will occur in the implementation of those. Keeping track of the schedule helps to see if the strategy is applied or not on the day of the month or not and check if we tend to drive on the right path to achieve the mission and vision. The opposite facet of project management is risk management, which helps the organization to review barriers or resistances and also offers the opportunity to overcome them. Therefore, it helps the organization to be prepared for any undue deviation from the established project (Singh, 2017).

It is essential that strategic projects implement strategies. It is because it is overshadowed by behavioral difficulties when implementing strategic projects. Apart from analytical struggles, problem solving and behavior management techniques would increase the efficiency of the project. These techniques are the cause of behavior analysis, analysis of the personal and strategic agenda, scenarios and the difficulty of behavior, energy curves and frustration over time (Grundy, 2000). Well- 
intentioned SPM can easily be budgeted for using strategies that are more likely to be unpredictable. However, those types of SPM are behavioral. There seems to be great merit in incorporating behavior problem-raising techniques into project management, especially for more strategic projects.

Strategic control activities allow organizations to observe and manage strategic processes. There are two types of strategic control systems: diagnostic controls and interactive controls. While diagnostic controls are often applied to motivate, monitor and reward the achievement of strategic objectives, interactive control systems include feedback mechanisms and therefore have the power to facilitate organizational learning and therefore, emerging elements such as new ideas or new strategic directions. Consequently, to influence "emerging action patterns," Simons recommends using interactive controls that specialize in addressing uncertainties that would affect the idea of competitive advantage. Other authors describe interactive control as a "means to emerge and act on emerging strategies that provides a framework for a more incremental and emergent approach to strategy formulation." However, it is important to note that interactive controls do not focus solely on popups. From a broader perspective, strategic controls contribute to the ability to measure performance while allowing organizations to manage and improve organizational performance (Kopmann et al., 2017).

Strategy Implementation and Portfolio Success Portfolio management can be a strategic management function that provides a bridge between strategy formulation and implementation (Meskendahl, 2010). The sum of the project investments determines the future of the organization in terms of shaping its structure, processes and products. Therefore, the organization's portfolio of projects represents the particular strategy being pursued. In the literature, three phases are described for the management of the project portfolio. The prioritization and selection of projects, the allocation of resources between projects and the management of the portfolio. Through these processes, portfolio management implements business strategy by coordinating decision-making on project investments, balancing risk and resources, and maximizing the value of the project portfolio (Kopmann et al., 2017).

According to Kopmann et al (2017) to shape the strategy, the existing strategy process is not enough. For organizational adaptability, evolving strategies have a top-down strategy process. The researchers examined the influence of the level of strategic 
control at the portfolio level. A sample of 182 organizations was collected to show that measured and evolving strategies influence portfolio success. Both types of strategies complement each other and are mediated by strategic control. In addition, it was found that there are three aspects of strategic control: premises control, implementation control, and traditional control. These aspects control the implementation of the expected and unexpected strategy.

At SPM, organizational barriers are a challenge when implementing project strategies. Project sustainability makes project managers think about their job security. Lack of SPM competency of PM practitioners causes to failures of project implementation. Decision-making power is also considered a challenge in SPM, as the project manager assumes many responsibilities in a project (Sabini \& Alderman, 2021). Based on anecdotal data published in the professional-oriented literature, the failure rate of PMO implementations is extremely high. Stanleigh (2016) states that "more than 75 percent of companies that established a PMO closed it after three years because it did not show any additional value" according to a study of 750 companies.

Similarly, Hobbs and Aubry (2007) stated that almost half of all PMOs were considered "too expensive and contribute little to the success of projects and programs" according to a $500 \mathrm{PM}$ survey. In fact, research has shown that PMOs are in most cases fragile structures, and companies often redesign their PMOs every few years (Hobbs et al., 2008). Based on these results, most companies will find it difficult to establish a PMO. A defined purpose, an agreed structure and governance scope, and whether the company culture is acceptable to a PMO appear to be important variables in the success of PMO implementation (Santosus, 2003; Wren, 2005).

According to Wren (2005), the PMO is likely to fail in the absence of a governance culture. According to Leemann (2002), "to be effective, project management must be part of the culture of a company." Kendall and Rollins (2003) identify seven reasons that can contribute to the failure of a PMO. These include: (1) not defining the PMO's value proposition, (2) a lack of perception of the PMO's effect on project execution skills, (3) The PMO has become too authoritarian, (4) The poor position of the PMO in the management reports. structure, (5) there has been no buy-in from top functional managers, (6) the PMO adds unnecessary overhead, and (7) the PMO is attempting to micromanage initiatives. 
It is now well established that the increasing popularity of program / portfolio management and the emergence of PMOs as an organizational form have fuelled an accelerated movement toward project-based organizational structures. Most organizations have implemented PMOs and portfolio management structures that have evolved from the traditional pyramid organizational structure. In this model, PMOs are playing a similar role to the quality department by monitoring and controlling project performance and developing the portfolio of project management (PM) methodologies and competencies and some PMOs are playing the role of finance by allocating resources throughout the organization. Hobbs and Aubry (2005) reported that "the organizational reality surrounding PMOs is complex and varied. Organizations establish a wide variety of different PMOs to cope with their reality".

Project initiatives and funding are usually located at the highest of the pyramid of a corporation, most often within the board of directors or the project office. Efficient funding secures good starting positions for the project and plays a task within the definition of the project domain, which is to an outsized extent determined by the corporate strategy and viewpoints of responsible managers. All this is often reflected in the project structure, delegations of individuals involved, the project budget and planned human resources. The project manager's scope of labour of the members of the team results from the defined undertakings, and therefore, the concrete influence on a project is defined by the degree of project authority and therefore the power enjoyed within the temporary organization (Cullen et al, 2015).

The management system of the project-oriented company provides an integrative management approach, supported by the application of the idea and practice of project management, strategic management, the PMO concept, change management, and leadership. Such a system enables the rise of executed projects and programs' effectiveness, which ends up increasing the effectiveness of the entire company. It's a crucial issue because the company's competitive advantage could be under threat by the following factors: globalization, new markets, the appliance of the latest organizational forms, and the development of data and communication technologies (Cullen, Calitz, \& Nel, 2015).

\section{Conclusion}

The paper has discussed the emergence of the SPM from OPM in organizations using existing SPM articles. Furthermore, studying the literature provided allowed us to 
gain a better understanding of the connections and links that exist between SPM and OPM. SPM describes "where" the organization has chosen to go, while OPM deals with "how" the organization will get there. It is obvious that the project goals must be linked to the strategic objectives in this situation. However, the most effective approach to ensuring that projects are aligned with strategy is to distinguish project goals from organizational objectives, since projects are initiated to put strategy into action, not the other way around.

Most of the time, strategies can be divided into tactics, which can then be put into action as programs. As a result, the projects would become part of a particular longterm strategic program. As a result, in every company, you must be able to link initiatives to particular organizational goals to demonstrate responsibility. The integrated SPM presented in this paper was considered as a contribution to close the gap between the OPM approach and the execution of the strategy to achieve greater efficiency.

The study contributed to exploring the concepts and applications of SPM in modern organizations and also discussed the challenges of organizations in practicing SPM. Additionally, the study highlighted the importance of SPM for the organization to achieve organizational strategic goals and competitive advantage. The study guides future researchers to conduct in-depth studies on SPM in today's organizations and to establish a theoretical basis for SPM to have a good understanding of the concept and practices of SPM.

Journal of Business Studies, 7(2)

$-111-$ 


\section{References:}

Aromataris, E. and Pearson, A., 2014. The systematic review: an overview. AJN The American Journal of Nursing, 114(3), pp.53-58.

Artto, K., Kujala, J., Dietrich, P., \& Martinsuo, M. (2008). What is project strategy?. International Journal of Project Management, 26(1), 4-12.

Aubry, M., Hobbs, B., \& Thuillier, D. (2007). A new framework for understanding organisational project management through the PMO. International journal of project management, 25(4), 328-336.

Aubry, M., Hobbs, B., \& Thuillier, D. (2008). Organisational project management: An historical approach to the study of PMOs. International Journal of Project Management, 26(1), 38-43.

Chen, M. (1994). Sun Tzu's strategic thinking and contemporary business. Business Horizons, 37(2), 42-49.

Cooke-Davies, T. J. (2004). Consistently doing the right projects and doing them right-What metrics do you need. The measured, 4(2), 44-52.

Cullen, M., Calitz, A. P., \& Nel, N. (2015). Project management for strategic management implementation in the energy sector. In 9th International Business Conference (IBC 2015) (pp. 1-19).

Denyer, D. and Tranfield, D., 2009. Producing a systematic review.

Dietrich, P., \& Lehtonen, P. (2005). Successful management of strategic intentions through multiple projects-Reflections from empirical study. International Journal of Project Management, 23(5), 386-391.

Fernez-Walch, S., \& Triomphe, C. (2004). L'approche plate-forme: filemanagement de familles de projets articulés autour d'éléments communs: composants, soussystèmes, plates-formes. Faire de la recherche en management de projet (Garel, Giard, Midler éditeurs), Vuibert, 247-279.

Grundy, T. (1998). Strategy implementation and project management. International Journal of Project Management, 16(1), 43-50.

Grundy, T. (2000). Strategic project management and strategic behaviour. International Journal of Project Management, 18(2), 93-103. 
Guertler, M. R., \& Sick, N. (2021). Exploring the enabling effects of project management for SMEs in adopting open innovation-A framework for partner search and selection in open innovation projects. International Journal of Project Management, 39(2), 102-114.

Ika, L. A., Söderlund, J., Munro, L. T., \& Landoni, P. (2018). When project management meets international development, what can we learn?. International Journal of Project Management, 2(36), 331-333.

Janka, T., \& Kosieradzka, A. (2019). The new approach to the strategic project management in the polish public administration. Foundations of Management, 11(1), 143-154.

Keinz, P., Hienerth, C., Gemünden, H. G., Killen, C. P., \& Sicotte, H. (2021). Managing open and user innovation by projects: Sensing, seizing and transforming.

Kendall, G. I., \& Rollins, S. C. (2003). Advanced project portfolio management and the PMO: multiplying ROI at warp speed. J. Ross Publishing.

Kerzner, H. (2019). Using the project management maturity model: strategic planning for project management. John Wiley \& Sons.

Kopmann, J., Kock, A., Killen, C. P., \& Gemünden, H. G. (2017). The role of project portfolio management in fostering both deliberate and emergent strategy. International Journal of Project Management, 35(4), 557-570.

Kozarkiewicz, A., \& Kabalska, A. (2016). Project Strategy and Strategic Project Management: The Understanding and the Perception of Relevance among Polish Project Management Practitioners. Project Management Development-Practice and Perspectives, 14, 187.

Kurtz, C. F., \& Snowden, D. J. (2003). The new dynamics of strategy: Sense-making in a complex and complicated world. IBM systems journal, 42(3), 462-483.

Lee, S. H., Peña-Mora, F., \& Park, M. (2006). Dynamic planning and control methodology for strategic and operational construction project management. Automation in construction, 15(1), 84-97.

Leemann, T. (2002). Project management: managing the chaos of change. Journal of business strategy. 
Marko, M., Dejan, P., \& Vladimir, O. (2006). Strategic Project Management-New Management Approach. International Scientific Days, 1.

Meskendahl, S. (2010). The influence of business strategy on project portfolio management and its success - A conceptual framework. International Journal of Project Management, 28(8), 807-817.

Mintzberg, H. (1979). An emerging strategy of" direct" research. Administrative science quarterly, 24(4), 582-589.

Morris, P., \& Jamieson, A. (2004). Traslating corporate strategy into project strategyRealizing corporate strategy through project management. Project Management Institute.

Økland, A., 2015. Gap analysis for incorporating sustainability in project management. Procedia Computer Science, 64, pp.103-109.

Papke-Shields, K. E., \& Boyer-Wright, K. M. (2017). Strategic planning characteristics applied to project management. International Journal of Project Management, 35(2), 169-179.

Patanakul, P., \& Shenhar, A. J. (2012). What project strategy really is: The fundamental building block in strategic project management. Project Management Journal, 43(1), 4-20.

Sabini, L., \& Alderman, N. (2021). The Paradoxical Profession: Project Management and the Contradictory Nature of Sustainable Project Objectives. Project Management Journal, 87569728211007660.

Santosus, M. (2003). Office Discipline: Why You Need a Project Management Office; Companies seeking more efficiency and tighter monitoring of IT projects are opening project management offices in growing numbers. But don't expect a quick fix, easy metrics or an immediate payback. CIO, 1-1.

Singh, S. (2017). Project Management and Strategic Objectives of the Organization. Universal Journal of Industrial and Business Management, 5(1), 10-12.

Stanleigh, M. (2016). From crisis to control: New standards for project management. Ivey Business Journal, 70(4), 1-4. 
Thiry, M., \& Matthey, A. (2005, February). Delivering business benefits through projects, programs, portfolios and PMOs. In Proceedings of PMI global congress, Singapore.

Vivek, R., \& Nanthagopan, Y. Extended Literature Review on Strategic Implementation Connecting to Public Sector Universities in Sri Lanka: An Initial Thematic Model.

Zolfaghari, S., Aliahmadi, A., \& Mazdeh, M. M. (2017). From strategy to project effectiveness: introducing the three stages of strategic project management. International Journal of Business Excellence, 12(3), 308-328. 